\title{
Study on Rubber Seal Design of a Swellpacker in Oil Well Cementing
}

\author{
Mingxin Ma1, Weijiang Jia ${ }^{2}$, Yuhuan $\mathrm{Bu}^{3}$, Shenglai Guo ${ }^{3}$ \\ ${ }^{1}$ Drilling Technology Research Institute of Shengli Oilfield Service Corporation, Sinopec, Dongying, China \\ ${ }^{2}$ Directional Drilling Company of Drilling Engineering Technology Company of Shengli Oilfield Service \\ Corporation, Dongying, China \\ ${ }^{3}$ China University of Petroleum, Qingdao, China \\ Email: mamingxinupc@163.com
}

Received 24 October 2014; revised 22 November 2014; accepted 5 December 2014

Copyright (C) 2014 by authors and OALib.

This work is licensed under the Creative Commons Attribution International License (CC BY).

http://creativecommons.org/licenses/by/4.0/

(c) (i) Open Access

\begin{abstract}
A swellpacker has the advantages of high isolation reliability and good gas migration resistance in open holes. This paper analyzed the contact pressure and stress distribution of the downhole swellpacker, and optimized rubber structure for various formations. 1) The research shows that thermal expansion can better explain the expanding process of the rubber after adsorption of oil. 2) The maximum contact pressure occurs in the middle of rubber, and the sealing effect of the packer increases exponentially with the length and thickness of rubber. 3) The shear stress model established for various formations indicates that the shear stress increases linearly with the contact pressure. According to the formation nature in northeastern Sichuan of China, 4) the optimum swellpacker rubber should be $18 \mathrm{~mm}$ in thickness, and $1.173 \mathrm{~m}$ in length for sandstone formation, $1.402 \mathrm{~m}$ for shale formation and $1.415 \mathrm{~m}$ for mudstone formation. 5) Stress verification reveals that the rubber does not fail and can work safely in downhole.
\end{abstract}

\section{Keywords}

Structure Design, Seal, Finite Element, Swellpacker

Subject Areas: Civil Engineering, Petrochemistry

\section{Introduction}

Swellpacker is a new type of self-swelling packer [1]. Its expanding mechanism is that the internal molecular structures of rubber expand [2] under thermal dynamic effect which allows liquid hydrocarbon to flow into the structures. It is capable of continuous swelling and can isolate irregular wellbore [3]. It can substitute for cementing job in lateral section of a horizontal well [4]. It is of simple structure, easy operation and high sealing 
reliability, which are conducive to improving completion efficiency and saving completion cost [5] [6]. Swellpacker represents the development trend of future packers.

International researches mainly focus on the influence of different temperature, pressure and chemical component [7] on rubber swelling, and its field application [8] [9], etc. Domestic researches mainly focus on the swelling test of Swellpacker [10]-[12], and more works are still needed.

At present, swellpacker structure design mainly depends on experience, swellpacker rubber length of Hallliburton and Weatherford differ from $0.5 \mathrm{~m}$ to $5 \mathrm{~m}$, no consideration was given to the sealing property of swellpacker in the well, and the influence of formation was not taken into consideration. Actually, the influence of formation on the sealing property of swellpacker is not negligible. It is simple and cost effective to design and optimize the structure of swellpacker under different formation with FEM method [13]. This paper analysed the contact pressure and stress distribution of swellpacker, based on the model of shear stress and contact pressure between formation and swellpacker, and optimized swellpacker rubber structure in different formations [14].

\section{Finite Element Analysis of Swellpacker}

Swellable rubber is made of lipophilic polymer material. Peculiar HNBR is mostly used in oil field as swellable rubber. The rubber test report was provided by LIANBANG RUBBER CO. LTD. Shore hardness of swellable rubber (Hs) is 80 , and the compression strength of rubber is $23.9 \mathrm{MPa}$.

\subsection{FEM Model of Swellpacker}

The structure of swellpacker is quite simple, and it is a layer of swellable rubber of a quick expansion vulcanized on the casing. An axisymmetric FEM model was established according to Well Yuanba 101 with central case, rubber, and formation, as shown in Figure 1.

The FEM model supposes that swellpaker could seal differential pressure of $20 \mathrm{MPa}$, pressure $40 \mathrm{MPa}$ on top and 40 - $60 \mathrm{MPa}$ from bottom. Center case was restrained on $\mathrm{x}, \mathrm{y}$ orientation, and the rubber was interference fitted between center case and formation.

The material parameters of rubber follows model M-R, the formations follows model DP, the rubber material applies element HYPER182, central case and formations applies element PLANE42, by free meshing, the boundary conditions between central case, rubber, and formation built rigid contact model by element CONTA175 and TARGE169.

\subsection{Swelling Description of Swellpacker}

Swellpacker inflates after absorbing oil, this is an equilibrium process of lipophilicity swelling and the elastic contraction of high molecular chains inside the rubber. In this progress, there are two reverse interactions which make swellable rubber reach equilibrium. Firstly, oil absorption makes 3D polymer network of rubber expand, while the entropy of rubber decreases because of such expanding of crosslinking polymer, the elastic contraction of polymer chains increases entropy of rubber.

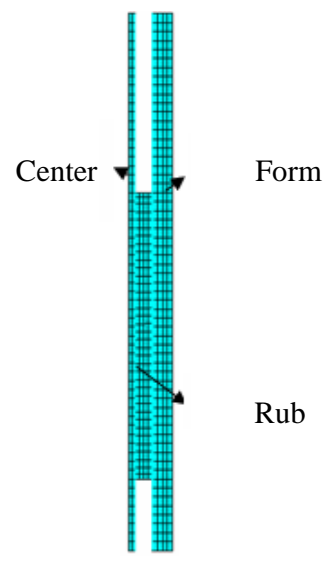

Figure 1. FEM model of Swellpaker. 
Similar to thermal dynamic swelling, this paper assumes the swelling of swellpacker to be thermal swelling with particular thermal expansion coefficient under particular thermal loads.

Based on a cylindrical rubber physical model established by A.S. Al-Yami [3], this paper analyzed the swelling progress under the thermal loads from temperature $20^{\circ} \mathrm{C}$ to $90^{\circ} \mathrm{C}$, the stress distribution of swelling rubber is shown in Figure 2.

As is shown in Figure 2, the maximum stress always occurs on lateral side of rubber, the stress ranges from $0.123 \times 10^{-14} \mathrm{MPa}$ to $0.944 \times 10^{-13} \mathrm{Mpa}$ which can be regarded as 0 . This shows that the stress has no change after the rubber swells, this characteristic is consistent with oil absorption swelling, thermal expansion can well simulate the absorption expanding process.

\subsection{The Contact Pressure Distribution}

Under top pressure of $40 \mathrm{MPa}$ and bottom pressure of $60 \mathrm{MPa}$, the contact pressure distribution with rubber of length of $0.8 \mathrm{~m}$ and interference thickness (rubber thickness under interference fit with formation after swellpacker swells) of $2.3 \mathrm{~mm}$ is shown in Figure 3. From Figure 3, the maximum contact pressure is located in the middle of rubber. The contact pressure and stress distribution of swellpacker will be introduced in detail [15].

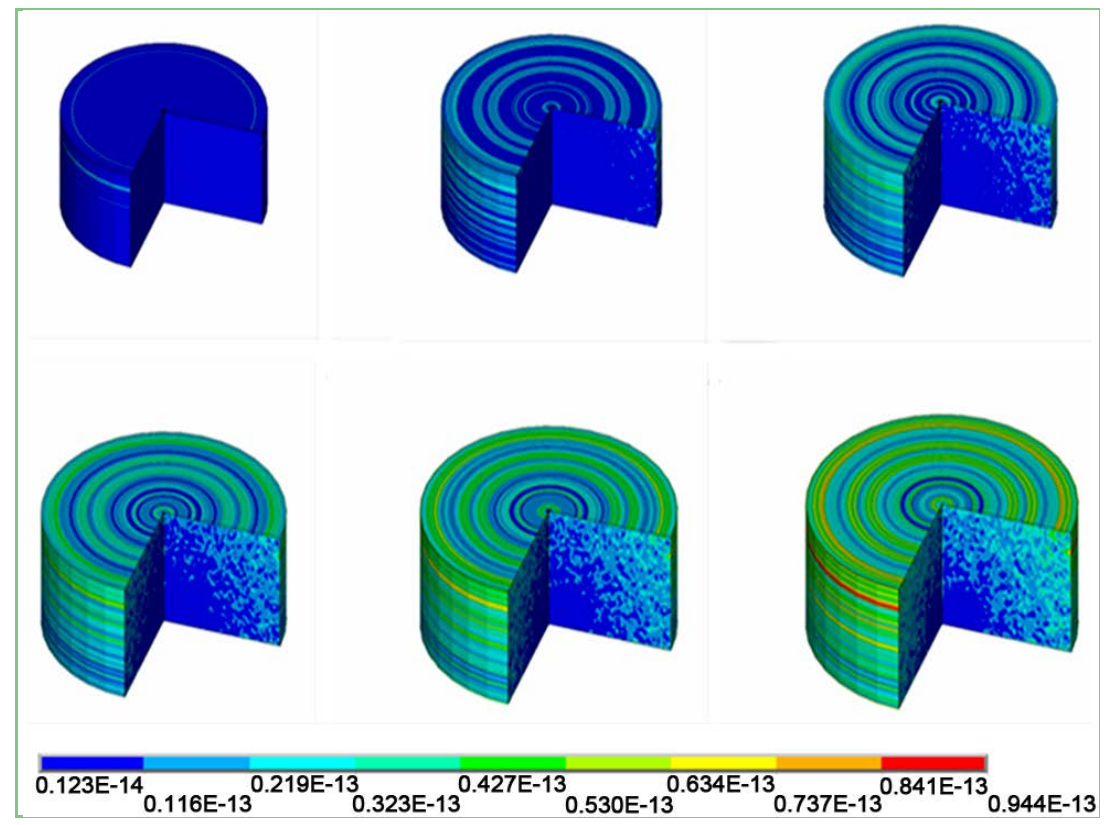

Figure 2. The stress distribution of swelling rubber in the swelling process (unit: $\mathrm{mm}$ ).
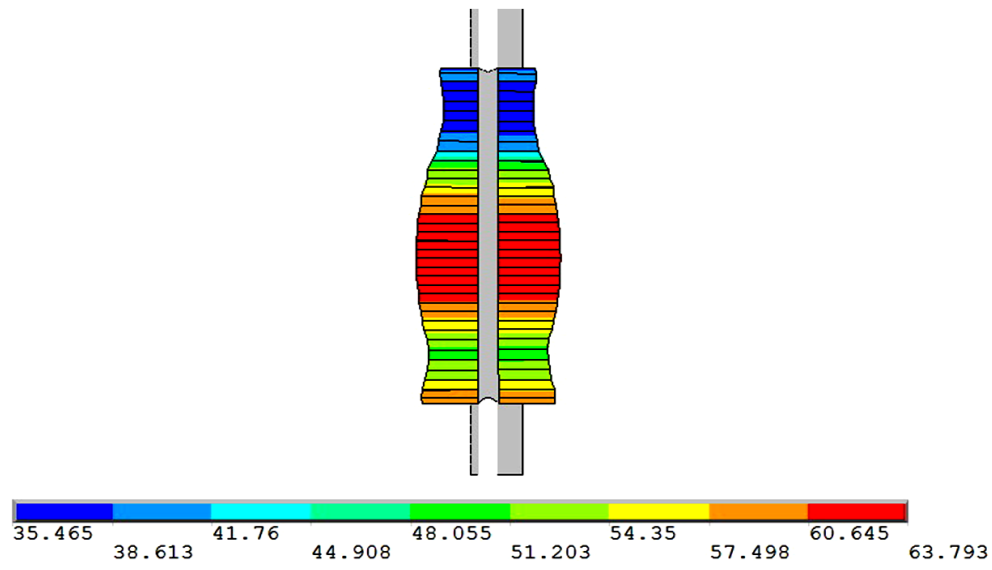

Figure 3. Contact pressure distribution (unit: Mpa). 


\section{Influence of Swellpacker Swelling on Formation}

Different formation has different effects on rubber sealing property. Contact pressure should be larger than gas channelling pressure of any side in order to cut off gas channel. As long as the contact pressure is larger than the pressure below packer, the packer can effectively isolate the pressure differential above and below the packer.

The sealing safety factor $(Z)$ is thus introduced, which means the ratio of the maximum contact pressure to the pressure below. If the sealing safety factor is greater than 1, it is regarded that the packer can seal effectively [16].

Assuming a packer is located at $4000 \mathrm{~m}$ below surface, under triaxial stress and the contact pressure of 60 $\mathrm{MPa}$, the shear stress distribution of borehole wall is shown in Figure 4. It can be seen that the max shear stress occurs along $45^{\circ}$ direction of the formation under triaxial stress, and the minimum stress along the vertical direction.

Taking sand stone, shale and mudstone formation for example, based on the FEM analysis, calculation model between the shear stress of formation and the contact pressure was established:

1) sand stone formation $\tau=0.64276 P-12.006$

2) shale formation $\tau=0.627 P-11.842$

3) mudstone formation $\tau=0.498 P-7.605$

where, $\tau$ : shear stress of formation, MPa; $P$ : contact pressure, MPa.

\section{Study on Sealing Effect and Optimization of Rubber Structure}

\subsection{Sealing Effect of Packer}

Based on FEM analysis, under the differential pressure of upper pressure of $40 \mathrm{MPa}$ and bottom pressure of 60 $\mathrm{MPa}$, different rubber length and different interference thickness, the maximum contact pressure in different formation were calculated, and corresponding sealing safety factors $(Z)$ were also calculated, as shown in Figure 5 and Figure 6 [17]. The sealing effect of packer increases exponentially with the length and thickness of rubber.

\subsection{Swelling Model of Rubber}

In the FEM analysis, rubber length and interference thickness were used, and the models of rubber length and interference thickness before and after packer's swelling was established. Based on data of Well Yuanba 101: hole size $d_{h}=241 \mathrm{~mm}$, casing OD $d_{\text {сои }}=193.7 \mathrm{~mm}$, swelling ratio of rubber length $\gamma_{l}=1.23$, swelling ratio of rubber thickness $\gamma_{i}=1.40 \quad$ [17], the models were established:

1) length model before and after packer's swelling:

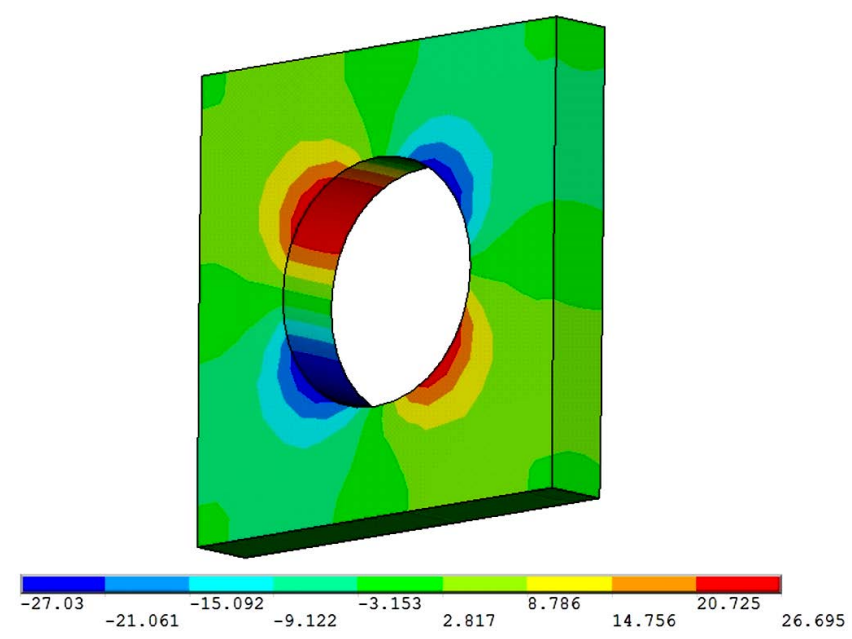

Figure 4. Shear stress distribution of borehole wall (unit: Mpa). 


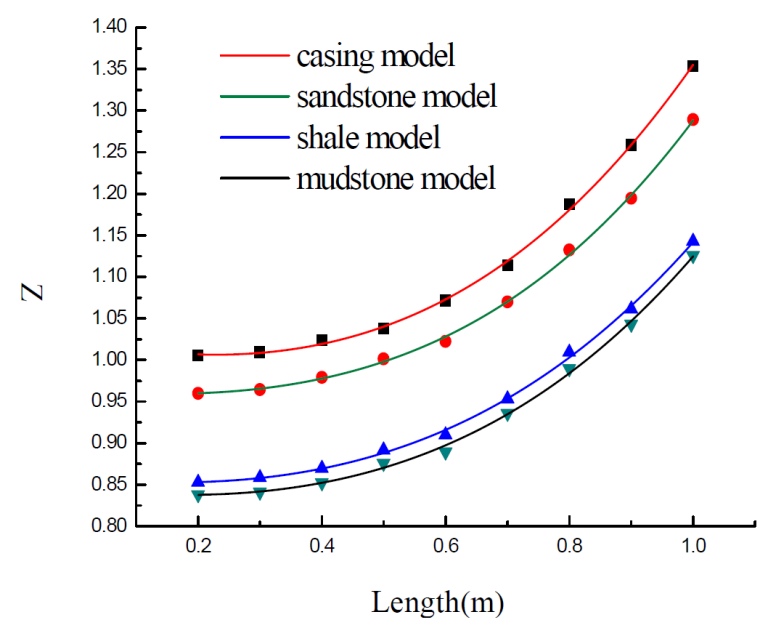

Figure 5. Relation between length of rubber and sealing safety facter.

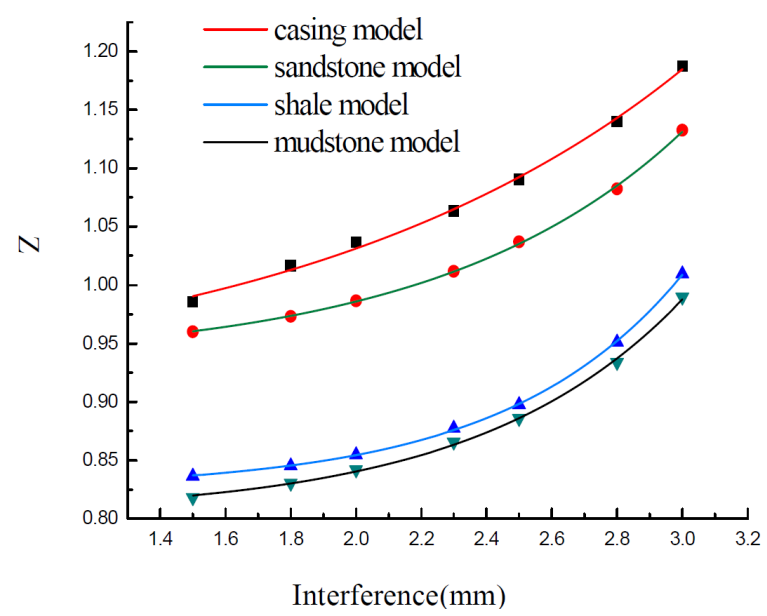

Figure 6. Relation between nterference thickness and sealing safety facter.

$$
l_{0}=\frac{l}{\gamma_{l}} \Rightarrow l=1.23 l_{0}
$$

where, $l_{0}$ : rubber length before packer's swelling, $\mathrm{m} ; \mathrm{l}$ : rubber length after packer's swelling, $\mathrm{m} ; \gamma_{l}$ : swelling ratio of rubber length $\left(\gamma_{l}>1\right)$.

2) thickness model before and after packer's swelling:

$$
i_{0}=\frac{\left(d_{h}-d_{\text {cou }}\right) / 2+i}{\gamma_{i}} \Rightarrow i=1.4 i_{0}-23.65
$$

where, $i_{0}$ : rubber thickness before packer's swelling, mm; $i$ : rubber interference thickness, mm; $d_{h}$ : hole size, $\mathrm{mm} ; d_{\text {соu }}$ : casing OD, mm; $\gamma_{i}$ : swelling ratio of rubber thickness $\left(\gamma_{i}>1\right)$.

In the actual application, it is suggested that the optimum rubber size before swelling be determined by the actual swelling ratio in the oil sample.

\subsection{Optimization of Rubber Structure for Different Formations}

Based on Figure 5, Figure 6 and formula (4), (5), nonlinear regression model between sealing safety factor and rubber structure in different formation were established as the following: 
1) sand stone formation: $Z=0.158941 \mathrm{e}^{3.647475 l_{0}+1.536894 i_{0}-31.36951}+0.918984 \quad\left(R^{2}=0.998579\right)$

2) shale formation: $Z=0.405443 \mathrm{e}^{2.7810711_{0}+1.406373 i_{0}-29.180297}+0.78106 \quad\left(R^{2}=0.989735\right)$

3) mudstone formation: $Z=0.442977 \mathrm{e}^{3.183265 l_{0}+1.63864 i_{0}-34.058764}+0.783351 \quad\left(R^{2}=0.994717\right)$

where, $Z$ : sealing safety factor; $l_{0}$ : rubber length before packer's swelling, $\mathrm{m} ; i_{0}$ : rubber thickness before packer's swelling, mm.

Under normal downhole conditions, packer can seal effectively when $S$ is greater than 1 . For higher reliability, the optimum sealing safety factor $Z_{\text {opt }}$ can be taken as 1.2 (The paper take 1.2 as the assumed one, and it can be varied for other situations, and the formula has been present.).

The paper gave the optimum rubber thickness with which the packer can be successfully run in hole:

1) Clearance between packer and formation should be greater than $5 \mathrm{~mm}$, and thickness before packer's swelling should be less than $18.65 \mathrm{~mm}$;

2) Packer should make contact with wellbore, thickness before packer's swelling should be greater than 16.89 $\mathrm{mm}$;

Hence, reasonable rubber thickness is between $16.89 \mathrm{~mm}$ and $18.65 \mathrm{~mm}$, take optimum rubber thickness $i_{0 o p t}$ as $18 \mathrm{~mm}$ that clearance between packer and formation is $5.65 \mathrm{~mm}$, interference thickness $i=1.55 \mathrm{~mm}$. When sealing safety factor $Z$ is taken as 1.2 , the optimum rubber length $l_{0 o p t}$ were calculated as below with formula (6), (7), and (8):

1) sand stone formation: $l_{0 o p t}=1.173 \mathrm{~m}$;

2) shale formation: $l_{0 o p t}=1.402 \mathrm{~m}$;

3) mudstone formation: $l_{0 o p t}=1.415 \mathrm{~m}$.

\section{Stress Verification of Packer Rubber}

The maximum stress of different rubber structure and formation were calculated by ANSYS, nonlinear regression model between the max stress and rubber structure before packer swelling are shown as below:

$$
\begin{aligned}
& \text { 1) sand stone formation: } \sigma_{\max } \ll 4.82665 l_{0}^{2}+0.0419 i_{0}^{2}-13.12628 \quad\left(R^{2}=0.951812\right) \\
& \text { 2) shale formation: } \sigma_{\max }=3.428433 l_{0}^{2}+0.02974 i_{0}^{2}-9.311619 \quad\left(R^{2}=0.949578\right) \\
& \text { 3) mudstone formation: } \sigma_{\max }=3.20403 l_{0}^{2}+0.027846 i_{0}^{2}-8.718837 \quad\left(R^{2}=0.949502\right)
\end{aligned}
$$

where, $\sigma_{\max }$ : the max stress of rubber, $(\mathrm{MPa}) ; l_{0}$ : rubber length before packer swelling, $\mathrm{m} ; i_{0}$ : rubber thickness before packer swelling, $\mathrm{mm}$.

Taking compression strength of Swellpacker as $23.9 \mathrm{MPa}$, and the max stress of rubber $\sigma_{\max }$ as $23.9 \mathrm{MPa}$, the stresses of different rubber structures were then calculated, based on the formula $Z_{R}=Z_{\max } / Z_{\text {opt }}$, the corresponding stress safety factor were calculated and shown as below:

1) sand stone formation: $\sigma_{z y}=7.0904 \mathrm{MPa}, Z_{R}=3.3707$;

2) shale formation: $\sigma_{z y}=6.9756 \mathrm{MPa}, Z_{R}=3.4262$;

3) mudstone formation: $\sigma_{z y}=6.7185 \mathrm{MPa}, Z_{R}=3.5573$.

$S_{\max }$ : the max stress of rubber, (MPa); $\sigma_{z y}$ : the stress of the optimum rubber structure, $(\mathrm{MPa}) ; Z_{R}:$ stress safety factor.

It can be seen that stress safety factor of optimum rubber structure in different formations are all greater than 1. Therefore, no failure occurs for the optimum rubber structure, and swellpacker can seal reliably.

\section{Conclusions}

1) Thermal expansion of swelling rubber is consistent with oil absorption expanding, thermal expansion can well simulate the absorption expanding process.

2) The maximum contact pressure is located in the middle of rubber. It slowly reduces towards the ends and then slowly increases. The sealing effect of packer increases exponentially with the increase in length and thickness of rubber. 
3) According to the formation characteristics in northeast of Sichuan province of China, swellpacker structure is optimized and has thickness of $18 \mathrm{~mm}$ and length of $1.173 \mathrm{~m}$ in sandstone formation, $1.402 \mathrm{~m}$ in shale formation and $1.415 \mathrm{~m}$ in mudstone formation. Stress verification proves that optimized swellpacker can work safely and no failure will occur in downhole.

\section{References}

[1] Noguera, J., Sierra, L. and Jorgensen, T. (2009) First Coiled Tubing Swellable-Packer Deployment in the Middle East. SPE/ICoTA Coiled Tubing \& Well Intervention Conference and Exhibition, 31 March-1 April 2009, The Woodlands.

[2] Kleverlaan, M., van Noort, R.H. and Jones, I. (2005) Deployment of Swelling Elastomer Packers in Shell E\&P. SPE/ IADC Drilling Conference, 23-25 February 2005, Amsterdam.

[3] Al-Yami, A.S., Nasr-El-Din, H.A. and Al-Saleh, S.H. (2008) Investigation of Oil Swelling Packers.

[4] Kennedy, G., Lawless, A. and Shaikh, K. (2005) The Use of Swell Packers as a Replacement and Alternative to Cementing. SPE Annual Technical Conference and Exhibition, 9-12 October 2005, Dallas.

[5] Antonio, L. and Barrios, O. (2007) Swelling Packer Technology Eliminates Problems in Difficult Zonal Isolation in Tight-Gas Reservoir Completion. Latin American \& Caribbean Petroleum Engineering Conference, 15-18 April 2007, Buenos Aires.

[6] Mahrooqi, M.A., Hinai, G. and Marketz, F. (2007) Improved Well and Reservoir Management in Horizontal Wells Using Swelling Elastomers. SPE Annual Technical Conference and Exhibition, 11-14 November 2007, Anaheim.

[7] Al-Yami, A.S., Awang, M.Z. and Al-Arfaj, M.K. (2008) Swelling Packers: Lab Testing and Field Application. International Petroleum Technology Conference, 3-5 December 2008, Kuala Lumpur.

[8] Helmy, M.W., Veselka, A. and Benish, T. (2006) Application of New Technology in the Completion of ERD Wells. SPE Russian Oil and Gas Technical Conference and Exhibition, 3-6 October 2006, Moscow.

[9] Freyer, R. (2002) Swelling Packer for Zonal Isolation in Open Hole Screen Completions. European Petroleum Conference, 29-31 October 2002, Aberdeen.

[10] Xu, X., Wei, X.F. and Yu, J.L. (2009) Researches and Applications of Oil/Water Expandable Packers. Petroleum Drilling Techniques, 37, 67-69.

[11] Wang, Q., Cao, A.-L. and Wang, P. (2003) Studies on Preparation and Properties of Oil Swelling Rubber. Polymeric Materials Science \& Engineering, 19, 206-208.

[12] Shen, Z.J., Gao, X.Q. and Tong, Z. (2010) Research and Application of the Self-Expandable Packer. China Petroleum Machinery, 38, 39-40, 43.

[13] Du, C.Q., Li, S.M. and Lv, H.R. (2008) Numerical Simulation and Structural Optimization of Stress for Packer Rubber. Fault-Block Oil \& Gas Field, 15, 104-106.

[14] Bu, Y.-H., Ma, M.-X. and Li, J.-H. (2011) Study on Sealing Property Judgement and Structure Design Method of Packer. Lubrication Engineering, 36, 75-78.

[15] Bu, Y.-H., Ma, M.-X. and Zang, Y.-B. (2011) Mechanics Simulated Analysis of Rubber of Swellpaker. China Petroleum Machinery, 39, 25-28.

[16] Ma, M.-X., Bu, Y.-H. and Cao, J.-F. (2012) Adaptation. Study between Swellpaker and Formation. China Petroleum Machinery, 40, 31-34.

[17] Ma, M.-X., Bu, Y.-H. and Cao, C.-Z. (2012) Study on the Sealing Property of Swellpaker. Lubrication Engineering, 7. 


\section{Nomenclature}

$d_{h}$ : hole size

$d_{\text {сои }}$ : casing OD

$i_{0}$ : rubber thickness before packer's swelling

$i$ : rubber interference thickness

$l_{0}$ : rubber length before packer's swelling

$l$ : length after packer's swelling

$l_{0 o p t}:$ the optimum rubber length

$P$ : contact pressure

$Z$ : sealing safety factor

$Z_{\text {opt }}$ : the optimum sealing safety factor

$Z_{R}$ : stress safety factor.

$\gamma_{i}$ : swelling ratio of rubber thickness

$\gamma_{1}$ : swelling ratio of rubber length

$\sigma_{\max }$ : the max stress of rubber

$\sigma_{z y}$ : the stress of the optimum rubber structure

$\tau$ : shear stress of formation 